Matthias Linnemann, Klaus-Peter Priebe, Gerhard Herres, Carsten Wolff, Jadran Vrabec

\title{
Design and test of a multi-coil helical evaporator for a high temperature organic Rankine cycle plant driven by biogas waste heat
}

Journal article | Accepted manuscript (Postprint)

This version is available at https://doi.org/10.14279/depositonce-9119



Linnemann, M., Priebe, K.-P., Herres, G., Wolff, C., \& Vrabec, J. (2019). Design and test of a multi-coil helical evaporator for a high temperature organic Rankine cycle plant driven by biogas waste heat. Energy Conversion and Management, 195, 1402-1414. https://doi.org/10.1016/j.enconman.2019.05.053 
This work is licensed under a CC BY-NC-ND 4.0 License (Creative Commons Attribution-

NonCommercial-NoDerivatives 4.0 International). For more information see

https://creativecommons.org/licenses/by-nc-nd/4.0/.

\title{
Design and test of a multi-coil helical evaporator for a high temperature organic Rankine cycle plant driven by biogas waste heat
}

\author{
Matthias Linnemann ${ }^{\mathrm{a}}$, Klaus-Peter Priebe ${ }^{\mathrm{b}, \mathrm{c}}$, Gerhard Herres ${ }^{\mathrm{b}}$, Carsten \\ Wolffc, Jadran Vrabec ${ }^{a, *}$ \\ ${ }^{a}$ Thermodynamics and Process Engineering, Technical University of Berlin, \\ Ernst-Reuter-Platz 1, 10623 Berlin, Germany \\ ${ }^{b}$ Thermodynamics and Energy Technology, University of Paderborn, Warburger Straße \\ 100, 33098 Paderborn, Germany \\ ${ }^{c}$ Dortmund University of Applied Sciences and Arts, Otto-Hahn-Straße 23, 44227 \\ Dortmund, Germany
}

\begin{abstract}
A direct evaporator for a high temperature organic Rankine cycle (ORC) plant with toluene as a working fluid is designed and tested. The exhaust gas from a $800 \mathrm{kWe}$ combined heat and power plant is cooled on the shell side of the present heat exchanger, while the working fluid is heated and evaporated within eight helically coiled tubes, constituting a tube bundle. A method to obtain optimal design parameters for this type of heat exchanger is presented, considering the heat source, the ORC and the available space at the test site. After manufacturing, the apparatus is tested to validate the design procedure, focusing on the employed heat transfer and pressure loss correlations on the shell side. It is shown that the predicted values of the overall heat transfer coefficient and the shell side Nusselt number are in good agreement with experimental data, showing a maximum deviation of $5.5 \%$. The measured shell side pressure loss is slightly higher than the predicted value, indicating that the correlation underestimates the pressure loss coefficient by up to $7 \%$ at low Reynolds numbers, but has a good accuracy at higher Reynolds numbers. It is observed that it is essential to adjust the mass flow rate of the working fluid in each coil to obtain a homogenous vapor
\end{abstract}

\footnotetext{
${ }^{*}$ Corresponding author

Email address: vrabec@tu-berlin.de (Jadran Vrabec)
} 
quality. A reliable operation of the direct evaporator with a maximum heat flow of $225 \mathrm{~kW}$ is shown.

Keywords: Direct evaporator, Organic Rankine cycle (ORC), Multi-coil helical heat exchanger, Waste heat recovery

2

\section{Introduction}

With a rising global demand for energy and the associated increase in fossil fuel consumption, dramatic environmental issues due to air pollution and climate change have emerged $[1,2]$. Much of the primary energy used in industrial applications is discharged to the environment in the form of waste heat $[3,4]$ so that there is a large potential for savings by exploiting such heat sources. Moreover, there are many renewable sources, e.g. geothermal, solar thermal or biomass combustion waste heat, that can be used to contribute to the development of a sustainable energy supply $[5,6,7]$. The organic Rankine cycle (ORC) is a promising technology for these objectives. Like the Rankine cycle that operates with water, the ORC converts a heat flow into mechanical power, but relies on other working fluids, which allow for the use of low temperature heat, simple cycle designs and the possibility of small scale power plants [8].

Despite the fact that the idea of using a working fluid other than water in steam engines already emerged in the early 19th century, the beginning of modern ORC research is based on the work of D'Amelio in the 1930s and led to a first commercial power plant in 1952 [9]. The rapidly growing number of publications until today [10] can serve as an indicator of the general interest in ORC technology and the need for its optimization. Most publications are of theoretical type and deal with the cycle design and the selection of an optimal working fluid [11]. As a key component, also various types of expanders were intensively studied $[12,13]$. Only limited research is available for heat exchangers directly related to the usage in ORC plants [14], although the evaporator is a particularly challenging component because its design has to be adopted closely to the heat source. On the one hand, a too small sized evaporator would yield incomplete evaporation, leading to an insufficient turbine output power or even damage, on the other hand an oversized evaporator correlates with too high investment costs. Most present ORC plants use an intermediate circuit to transfer heat from the source to the working fluid [10], which entails high investment costs and space require- 
ments. In addition, a substantial part of the exergy is lost and the achievable efficiency is reduced, since the maximum temperature of the working fluid decreases and also mechanical power for the intermediate cycle pump is needed [15]. In this context, mainly shell and tube heat exchangers are used with the working fluid on the shell side, resulting in a high hold up. Alternatively, heat can be transferred directly from the source to the working fluid, thereby increasing efficiency and reducing costs. However, such a design may lead to a more susceptible operating performance due to temperature fluctuations and a conceivable shortening of the working fluid operating time because of thermal decomposition at hot spots in the evaporator [16]. In the case of direct heat transfer, usually once-through heat exchangers are used with straight finned tubes, in which the working fluid flows through the tubes [17]. Another type is the shell and helical tube heat exchanger, where the working fluid also flows within the tubes. Compared to heat exchangers with straight tubes, those of the shell and helical tube type are described as advantageous in terms of better heat transfer, caused by a secondary flow inside the tubes [18] and a more compact size, but the secondary flow also leads to a higher pressure loss. Although this type of heat exchanger is well known and often used in food and chemical processing as well as in nuclear reactors for steam generation [19], its use in connection with ORC systems has hardly been documented in research.

Kosmadakis et al. [20] and Kaya et al. [14] employed a helical coil heat exchanger as an evaporator in a low temperature solar thermal ORC plant, where heat transfer takes place from hot liquid water on the shell side to a single tube coil filled with working fluid. In the high temperature range, especially for the utilization of exhaust gas waste heat, for which Hatami et al. [21] reviewed different types of evaporators, only one publication by Wang et al. [22] is known, where a multi-coil evaporator was used in an ORC test rig. However, their focus lied on the holistic experiment, but details on the design parameters and the heat transfer behavior of the heat exchanger were not presented.

For these reasons, it seemed worthwhile to investigate this type of evaporator in conjunction with ORC technology, which was carried out in the present work for a planned high temperature ORC plant, which used toluene as a working fluid and was driven by waste heat from a biogas combined heat and power plant (CHP). In the following, the biogas plant with a maximum electrical output of $800 \mathrm{kWe}$ and an exhaust gas temperature of up to $519^{\circ} \mathrm{C}$ is analyzed together with the operating points of the ORC to determine the 
requirements for the evaporator. Subsequently, the design procedure for an efficient and compact evaporator is described in detail, including a discussion of the employed heat and pressure loss correlations from the literature. The nominal heat flow transferred from the exhaust gas on the shell side to eight tube coils, filled with toluene, is studied. The results and observations that were obtained after manufacturing of the full scale heat exchanger and the following field tests are discussed to validate the design parameters. Consequently, the present work provides a suitable procedure for the design of an innovative direct evaporator in the field of ORC technology and describes its operational behavior.

\section{Design of the helical coil evaporator}

The present evaporator is a direct coupling device between the heat source and the ORC working fluid. Therefore, it has an influence on the performance and reliability of two complex plants at the same time so that an appropriate design is crucial. For the present scenario, the heat source and the ORC are thus described and analyzed in the following.

\subsection{Heat source}

The exhaust gas of a biogas CHP served as the heat source in the present work. A 16 cylinder V-type combustion engine by MWM with a generator set used biogas as a fuel and had a maximum electrical power output of 800 kWe. The engine power was adapted to the fluctuating electrical energy demand and was often operated with semi load. This boundary condition must not affect the operational capability of the ORC and thus had to be considered in the evaporator design process. Important parameters for three load conditions of the engine, as given by the CHP supplier [23], are listed in Tab. 1. The exhaust gas temperature was in a range between 468 and $519^{\circ} \mathrm{C}$ and increased with decreasing load. Assuming its exploitation down to $150^{\circ} \mathrm{C}$, the exhaust gas heat load was between 257 and $419 \mathrm{~kW}$, which corresponds to $22-25 \%$ of the primary fuel energy. Furthermore, it was necessary to know the composition of the exhaust gas, which can be calculated from the known composition of the biogas, being a mixture of methane $\left(\mathrm{CH}_{4}\right)$ and carbon dioxide $\left(\mathrm{CO}_{2}\right)$, and had a volume fraction of $52 \%$ and $48 \%$, respectively, in the present scenario. Complete combustion can be assumed with an air fuel ratio of 1.69 that leads to a calculated molar exhaust composition of $70.3 \%$ nitrogen $\left(\mathrm{N}_{2}\right), 11.2 \%$ water $\left(\mathrm{H}_{2} \mathrm{O}\right), 10.8 \% \mathrm{CO}_{2}$ and $7.7 \%$ oxygen $\left(\mathrm{O}_{2}\right)$. For this 
exhaust gas mixture, the highly sophisticated GERG-2008 equation of state [24] allowed for the calculation of temperature-dependent thermodynamic properties, except for the transport coefficients. The dynamic viscosity of the mixture $\eta_{m}$ was determined with the method of Wilke [25]

$$
\eta_{m}=\sum_{i=1}^{n} \frac{y_{i} \eta_{i}}{\sum_{j=1}^{n} y_{j} \Phi_{i j}},
$$

with mole fraction $y_{i}$, dynamic viscosity $\eta_{i}$ of the pure component $i$, the binary interaction parameter

$$
\Phi_{i j}=\frac{\left(1+\left(\eta_{i} / \eta_{j}\right)^{1 / 2}\left(M_{j} / M_{i}\right)^{1 / 4}\right)^{2}}{\left(8\left(1+M_{i} / M_{j}\right)^{1 / 2}\right.},
$$

and the molar masses $M_{i}$ and $M_{j}$ of the pure components $i$ and $j$, respectively. The thermal conductivity $\lambda_{m}$ was calculated following Mason and Saxena [26]

$$
\lambda_{m}=\sum_{i=1}^{n} \frac{y_{i} \lambda_{i}}{\sum_{j=1}^{n} y_{j} A_{i j}},
$$

where $\lambda_{i}$ is the thermal conductivity of the pure component $i$ and the binary interaction parameter $A_{i j}$ is analogous to $\Phi_{i j}$ in Eq. (2), substituting $\lambda_{i}$ for $\eta_{i}$. The dynamic viscosity and thermal conductivity data of the pure components were obtained from highly accurate equations of state [27, 28, 29, 30, 31]. To ensure a safe plant operation of the CHP, its supplier specified that the pressure loss in the entire exhaust gas line must not exceed 25 mbar. Considering a catalytic converter and a muffler that also cause pressure loss, the maximum permissible pressure loss on the exhaust side of the evaporator was limited to 15 mbar in consultation with the CHP supplier. Furthermore, the outlet temperature of the exhaust gas should not be below $120^{\circ} \mathrm{C}$ to avoid water condensation.

\subsection{Organic Rankine cycle}

Fig. 1 shows the schematic structure of the planned ORC plant with toluene as a working fluid and an expected output power of $40 \mathrm{kWe}$. Beside the direct evaporator that was investigated in the present work, the other key components were a turbine, a recuperator, a condenser, which discharges the heat to a water-glycol mixture, and a feed pump. Given by a preliminary design of the ORC, toluene entered the heat exchanger with a temperature 
Table 1: Different load conditions of the present CHP.

\begin{tabular}{lllll}
\hline Load & 100 & 75 & 50 & $\%$ \\
\hline Electrical power output & 800 & 600 & 400 & $\mathrm{~kW} \pm 8 \%$ \\
Jacket water heat load & 421 & 335 & 258 & $\mathrm{~kW} \pm 8 \%$ \\
Exhaust gas heat load & 419 & 343 & 257 & $\mathrm{~kW} \pm 8 \%$ \\
Exhaust gas temperature & 468 & 492 & 519 & ${ }^{\circ} \mathrm{C}$ \\
Mass flow of exhaust gas & 1.1808 & 0.8956 & 0.6192 & $\mathrm{~kg} / \mathrm{s}$ \\
Fuel consumption & 1916 & 1479 & 1047 & $\mathrm{~kW}+5 \%$ \\
Electrical efficiency & 41.8 & 40.6 & 38.2 & $\%$ \\
Total efficiency & 63.7 & 63.2 & 62.8 & $\%$ \\
\hline
\end{tabular}

of $155.5^{\circ} \mathrm{C}$ and a pressure of 17.5 bar to be heated, evaporated and with a degree of $3 \mathrm{~K}$, slightly superheated up to a temperature of $255^{\circ} \mathrm{C}$, while the pressure loss should be small in order to obtain a high efficiency. The working fluid mass flow rate at the nominal design point was $0.56 \mathrm{~kg} / \mathrm{s}$, which leads to a necessary heat input of $263 \mathrm{~kW}$. In addition to this basic information, the proposed working fluid had to be considered in terms of safety and environmental issues. Toluene, whose basic properties are listed in Tab. 2, is a hydrocarbon that is hazardous to health and aquatic life. It has an autoignition temperature of $535^{\circ} \mathrm{C}$ [32], which is higher than the maximum temperature of the exhaust gas. Andersen et al. [33] studied the thermal stability of toluene at a temperature of $315^{\circ} \mathrm{C}$, obtaining a decomposition rate of 3.3 years for the loss of $50 \%$ of the pure fluid. Beneficial characteristics of toluene are its zero ozone depletion potential (ODP) and global warming potential (GWP) [34]. Based on these considerations, the use of a direct evaporator that is in compliance with safety regulations was assessed to be feasible for the planned ORC plant.

\subsection{Design method for the heat exchanger}

The evaporator was designed for the nominal capacity of the planned ORC plant and thus for a maximum heat transfer of $263 \mathrm{~kW}$. The input parameters for the working fluid side were known from the analysis of the ORC. On the shell side, a part of the cooled exhaust gas was took off after the evaporator and fed back into the hot stream, reducing the inlet temperature and minimizing the risk of thermal decomposition of toluene at hot spots. Furthermore, the mass flow rate was increased by this measure, leading to a better heat transfer. For a typical CHP power output of $600 \mathrm{kWe}$, an 


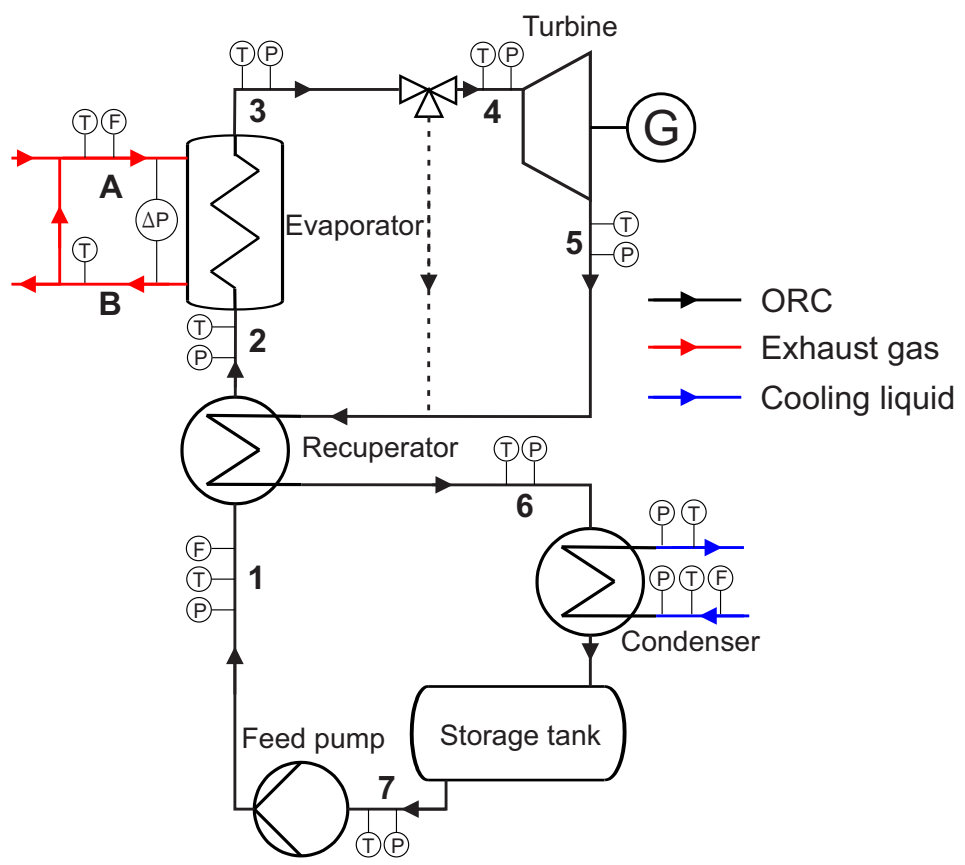

Figure 1: Process flow diagram of the planned ORC plant.

Table 2: Properties of toluene.

\begin{tabular}{lc}
\hline Chemical formula & $\mathrm{C}_{7} \mathrm{H}_{8}$ \\
CAS number & $108-88-3$ \\
Molecular weight & $92.138 \mathrm{~g} / \mathrm{mol}$ \\
Critical temperature & $318.60^{\circ} \mathrm{C}$ \\
Critical pressure & $41.263 \mathrm{bar}$ \\
Autoignition temperature & $535^{\circ} \mathrm{C}$ \\
ODP & 0 \\
GWP & 0 \\
\hline
\end{tabular}


exhaust gas inlet temperature of $378^{\circ} \mathrm{C}$ and an outlet temperature of $192^{\circ} \mathrm{C}$ leads to a mass flow rate of $1.32 \mathrm{~kg} / \mathrm{s}$ at a pressure of 1.03 bar. The heat flow from the exhaust was assumed to be $277 \mathrm{~kW}$ to compensate for heat loss to the environment of $5 \%$. From these input parameters, a temperature profile emerges as shown in Fig. 2, where it becomes apparent that the heat exchanger can be divided into three sections, namely the preheating of liquid toluene, its evaporation and superheating. Further, the pinch point temperature difference (PPTD) with a value of $32 \mathrm{~K}$ occured at the beginning of evaporation.

A schematic of the heat exchanger is depicted in Fig. 3. It consists of an inner and an outer shell with an annulus in between, providing space for the exhaust gas flow and the tube bundle. The latter was made of multiple coils with a staggered layout. The arrangement of multiple coils, in which the flow of the working fluid distributes, was a particular challenge in subsequent calculations. Due to the smallest diameter of the inner coil, its total length and thus the flow resistance inside the tube were the lowest. Consequently, the working fluid mass flow would decrease from the inner to the outer coils, while the heat transfer area increases, resulting in an incomplete evaporation in the inner coils and a high degree of superheating in the outer coils. To prevent this and to obtain the same temperature and vapor quality at the exit of each coil, the flow rates had to be adjusted with valves in front of the coils.

The design process was conducted with the logarithmic mean temperature difference (LMTD) method, which describes the heat transfer $\dot{Q}_{\text {LMTD }}$ from the exhaust to the working fluid with

$$
\dot{Q}_{\mathrm{LMTD}}=k A_{\mathrm{HT}} \Delta T_{\mathrm{ln}}=k A_{\mathrm{HT}} \frac{\Delta T_{1}-\Delta T_{2}}{\ln \left(\Delta T_{1} / \Delta T_{2}\right)},
$$

where $k$ is the overall heat transfer coefficient, $A_{\mathrm{HT}}$ the heat transfer area and $\Delta T_{\ln }$ the logarithmic mean temperature difference with the temperature differences $\Delta T_{1}$ and $\Delta T_{2}$ between the fluids at the heat exchanger inlet and outlet, respectively.

The overall heat transfer coefficient for the tubes was determined following Baehr and Stephan [35]

$$
k=\left(\left(\frac{1}{\alpha_{i} r_{i}}+\ln \left(\frac{r_{o}}{r_{i}}\right) \frac{1}{\lambda_{S}}+\frac{1}{\alpha_{o} r_{o}}\right) \frac{r_{o}+r_{i}}{2}\right)^{-1},
$$




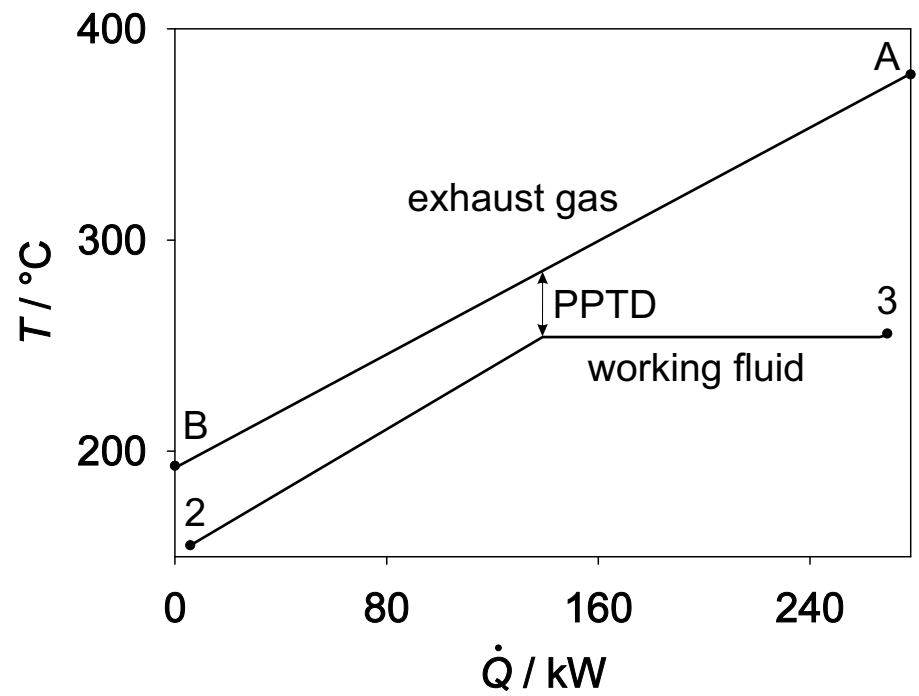

Figure 2: Heat transfer in the direct evaporator, following the state point numbering introduced in Fig. 1. The working fluid toluene was heated, evaporated and superheated with an overall load of $263 \mathrm{~kW}$.

where $\alpha_{i}$ and $\alpha_{o}$ are the heat transfer coefficients inside and outside the tube, respectively, $r_{i}$ the inner and $r_{o}$ the outer tube radii and $\lambda_{S}$ the thermal conductivity of the wall material that was assumed to be $17 \mathrm{~W} /(\mathrm{mK})$ for the employed stainless steel (EN 1.4571) [36]. For comparable appliances, e.g. shell and U-tube heat exchangers, it is known from the literature [37] that the heat transfer coefficient at the outside of a tube bundle, which is in contact with a gas flow, is low compared to values inside the tube so that $\alpha_{o}$ represents the main heat resistance dominating the overall heat transfer coefficient. A preliminary estimation of $\alpha_{o}$ in a range between 100 and 200 $\mathrm{W} /\left(\mathrm{m}^{2} \mathrm{~K}\right)$ and $\alpha_{i}$ with values above $1000 \mathrm{~W} /\left(\mathrm{m}^{2} \mathrm{~K}\right)$ confirmed this finding. This implies that the heat exchanger design should aim at a high shell side heat transfer coefficient to increase the value of $k$ and consequently allow for a small heat transfer surface $A_{\mathrm{HT}}$ at given $\dot{Q}$ and $\Delta T_{\mathrm{ln}}$, cf. Eq. (4). A small heat transfer area correlates with a low demand for steel material, reducing costs for the heat exchanger.

For the estimation of $\alpha_{o}$, an approach of Gnielinski [38] was used in the present work, where 



Figure 3: Schematic cutaway drawing of a shell and multi-coil helical heat exchanger. 


$$
\alpha_{o}=\frac{\mathrm{Nu}_{\text {bundle }} \lambda_{m}}{l},
$$

205

with the characteristic length

$$
l=\frac{\pi}{2} d_{o},
$$

206 207

210

211

with a laminar contribution

$$
\mathrm{Nu}_{1, \mathrm{lam}}=0.664 \sqrt{\operatorname{Re}_{\Psi, 1}} \sqrt[3]{\mathrm{Pr}},
$$

212 and a turbulent contribution

$$
\mathrm{Nu}_{1, \text { turb }}=\frac{0.037 \operatorname{Re}_{\Psi, 1}^{0.8} \operatorname{Pr}}{1+2.443 \operatorname{Re}_{\Psi, 1}^{-0.1}\left(\operatorname{Pr}^{2 / 3}-1\right)} .
$$

${ }_{213}$ The Reynolds number $\operatorname{Re}_{\Psi, 1}$ in the range $10<\operatorname{Re}_{\Psi, 1}<10^{6}$ is

$$
\operatorname{Re}_{\Psi, 1}=\frac{w l \rho_{m}}{\Psi \eta_{m}},
$$

214 where $w$ is the flow velocity in the free shell annulus, $\rho_{m}$ the density of the 215 gas mixture and $\Psi$ the void fraction in the shell that is determined with

$$
\begin{gathered}
\Psi=1-\frac{\pi}{4 a} \text { for } b \geq 1, \quad \text { and } \\
\Psi=1-\frac{\pi}{4 a b} \text { for } b<1,
\end{gathered}
$$


with the horizontal split ratio $a=s / d_{o}$, while the parameter $s$ is defined in Fig. 3.

From these relationships, it becomes apparent which parameters have an influence and how they have to be modified in order to increase the heat transfer coefficient on the shell side of the heat exchanger. The main factor of influence is the gas velocity that is taken into account by the velocity within the free shell annulus $w$, and its increase entails a better heat transfer. Reducing the area of the shell annulus by varying the inner and outer shell diameters leads to higher values of $w$. Indeed, the tube bundle is located within the free shell annulus, leading to a reduced flow section and consequently to a higher velocity, which is considered by the shell void fraction $\Psi$. The closer the tubes are arranged to each other, the smaller the value of $\Psi$, which in turn leads to an increasing heat transfer coefficient. Another variable is the tube dimension due to the characteristic length $l$, cf. Eqs. (6) and (13), defined by the outer tube diameter that also characterizes the entire arrangement of the tube bundle.

However, some requirements limited the maximum value of the outer heat transfer coefficient. The main restriction was the maximum permissible pressure drop of the exhaust gas that was 15 mbar for the entire evaporator. Considering a feed and exit passage, the pressure drop caused by the tube bundle should not exceed 10 mbar. Since the pressure drop correlates with gas velocity, the free shell annulus and the space between the tubes in the bundle may not be reduced arbitrarily. Moreover, an increasing tube bundle length leads to an increasing pressure drop. For practical reasons at the test site, the maximum diameter of the apparatus, including its insulation, was $1.2 \mathrm{~m}$, leading to a maximum diameter of $0.8 \mathrm{~m}$ of the outer shell, while the height of the tube bundle was limited to $2.5 \mathrm{~m}$. In terms of the manufacturing process, the minimum diameter of the inner shell was set to $0.35 \mathrm{~m}$, the spacing between each coil was at least $2 \mathrm{~mm}$ and only standard tube dimensions were considered in the design process. The basic input parameters are summarized in Tab. 3 .

The LMTD design approach is based on averaged thermodynamic properties so that the heat exchanger was discretized into segments, in which the variation of properties was small enough to assume that it occurs stepwise. In the present work, the tube bundle was discretized in segments with a height of $0.15 \mathrm{~m}$ for the preheater, where the heat flux was low, and $0.05 \mathrm{~m}$ for the evaporator and superheater section, respectively, where higher heat fluxes occurred. For the estimation of an appropriate tube arrangement and the 
Table 3: Basic input parameters for the tube bundle design process.

\begin{tabular}{lcll}
\hline \multicolumn{2}{l}{ Parameters } & & Unit \\
\hline Minimum inner shell diameter $D_{S, i}$ & & 0.35 & $\mathrm{~m}$ \\
Maximum outer shell diameter $D_{S, o}$ & & 0.8 & $\mathrm{~m}$ \\
Maximum height of tube bundle & 2.5 & $\mathrm{~m}$ \\
Minimum spacing between each coil & & 0.002 & $\mathrm{~m}$ \\
Maximum exhaust pressure drop & 10 & $\mathrm{mbar}$ \\
Thermal conductivity of tube material & & 17 & $\mathrm{~W} /(\mathrm{mK})$ \\
\hline Fluid & Toluene & Exhaust gas & \\
\hline Mass flow & 0.56 & 1.32 & $\mathrm{~kg} / \mathrm{s}$ \\
Pressure & 17.5 & 1.03 & $\mathrm{bar}$ \\
Inlet temperature & 155.5 & 378 & ${ }^{\circ} \mathrm{C}$ \\
Outlet temperature & 255 & 192 & ${ }^{\circ} \mathrm{C}$ \\
\hline
\end{tabular}

shell side design, the heat transfer coefficient on the tube inside was initially assumed to be constant with $\alpha_{i}=1000 \mathrm{~W} /\left(\mathrm{m}^{2} \mathrm{~K}\right)$. The calculation process, which is illustrated by a schematic flow chart in Fig. 4, was initiated with the first segment of the preheater, where the inlet temperature of the working fluid and the outlet temperature of the exhaust gas were known. For a first iteration, the exhaust inlet temperature was assumed so that the heat flow $\dot{Q}_{\mathrm{EB}}$ was obtained by an energy balance. Based on these data, the outlet temperature of the working fluid was estimated, leading to $\Delta T_{\mathrm{ln}}$. The heat transfer area in the segment was calculated for the specified tube bundle and subsequently, the heat transfer coefficient on the shell side was calculated as described by Eqs. (6) to (15), yielding the overall heat transfer coefficient $k$ and thus the transferred heat flow $\dot{Q}_{\mathrm{LMTD}}$. Subsequently, the exhaust inlet temperature was adjusted until the difference between the heat flow from the energy balance and heat transfer calculation was minimal and converged below a threshold value. The obtained fluid states were transferred as inputs for the subsequent segment. When the working fluid reached a saturated liquid state, the height of that specific segment was adjusted until the outlet enthalpy value converged to the saturated liquid enthalpy. Subsequently, this procedure was continued for the evaporator and the superheater until the working fluid temperature attained the required value. Summarizing the segment heights, the total height of the tube bundle and the total tube length was estimated.

Finally, the pressure drop of the exhaust gas in each segment was deter- 


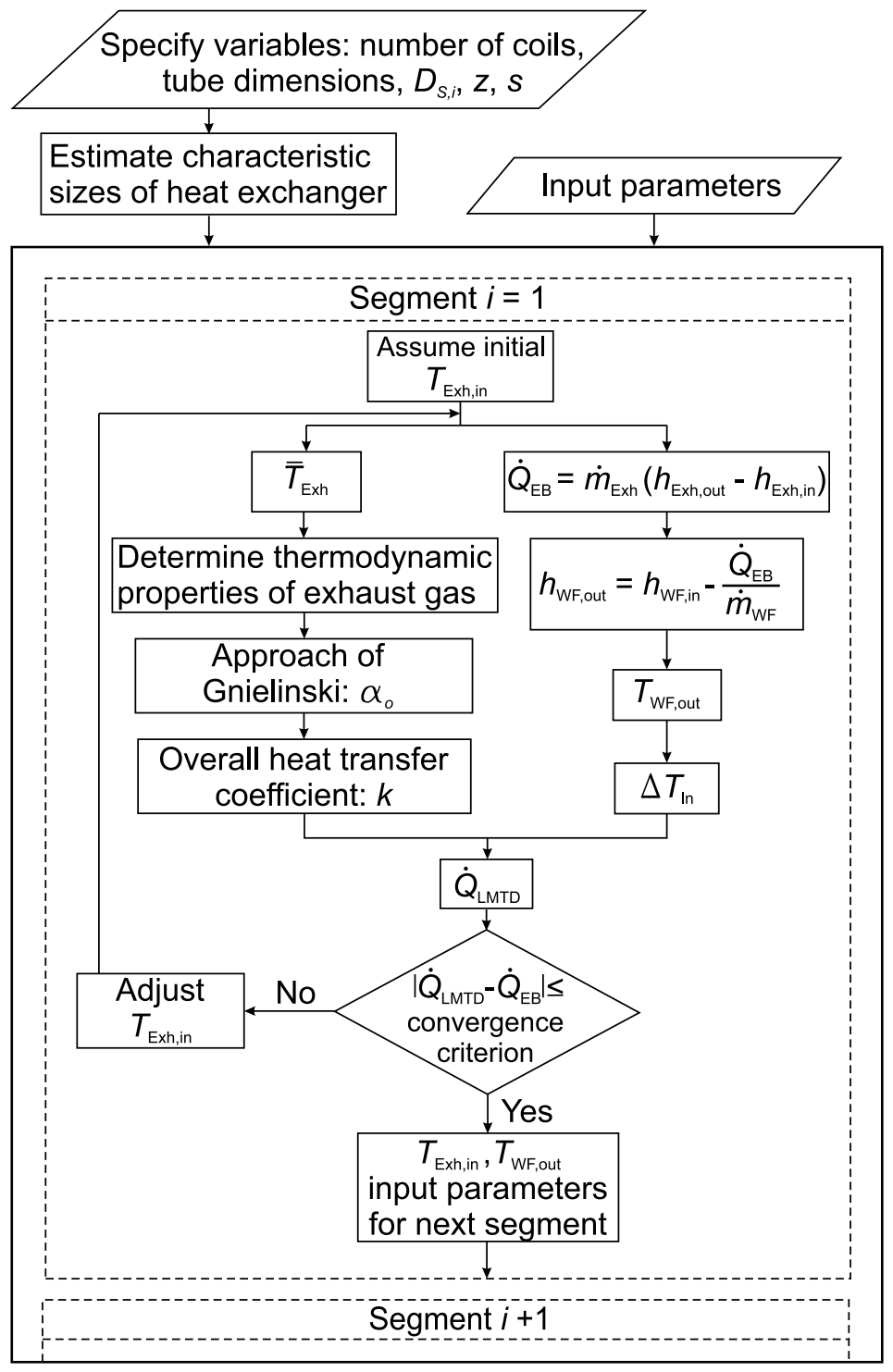

Figure 4: Schematic flow chart of the heat transfer calculation with the LMTD method to determine a favorable shell and tube bundle design. 
mined following an approach of Gaddis and Gnielinski [39]

$$
\Delta p_{\mathrm{Exh}}=\xi n_{W} \frac{\rho_{m} w_{n}^{2}}{2},
$$

where $\xi$ is the pressure loss coefficient, $n_{W}$ the number of windings in a segment and $w_{n}$ the gas velocity in the narrowest flow section. The detailed calculation of these parameters is described in the Appendix. By summarizing the pressure losses in all segments, the total pressure loss in the tube bundle was obtained.

Calculations were conducted for tube bundles with a number of 4 to 10 coils and tubes with a nominal size of DN 10, DN 15 and DN 20. Fig. 5 presents the results for the averaged outside heat transfer coefficient, the height of the tube bundle to transfer the required heat and the associated exhaust gas pressure loss. The values of $\bar{\alpha}_{o}$ decrease with an increasing number of coils and with an increasing tube diameter. This is a consequence of lower gas velocities in bundles with a higher number of coils and larger tube diameter. The resulting height of the tube bundle decreases with an increasing number of coils due to the heat transfer area enlargement. However, the low outside heat transfer coefficient for larger tube diameter correlates with higher tube bundles. The maximum tube bundle height of $2.5 \mathrm{~m}$ is marked in Fig. 5 and illustrates that the minimum number of coils to comply with this limit was 7, 8 and 10 coils for the nominal tube sizes DN 10, DN 15 and DN 20, respectively. The results for the exhaust gas pressure drop within the tube bundle show that a low number of coils and small tube diameter lead to a high pressure loss. Considering the upper limit of 10 mbar, it became apparent that only configurations with a nominal tube size of DN 10 and 9 or 10 coils, as well as a tube size of DN 15 with 8 coils were possible, while the combinations of DN 15 with 9 and 10 coils and also the DN 20 with 10 coils exceeded the maximum outside shell diameter of $0.8 \mathrm{~m}$. Furthermore, it was observed that the tube arrangement should be as close as possible, accomplished by small values of $z$ and $s$, and that the diameter of the inner shell should be at its minimum limit, leading to beneficial heat transfer results.

Based on these findings, a precise design calculation was carried out for the tube bundle arrangements, by also taking into account correlations for the heat transfer coefficient within the tubes and by determining the pressure drop of the working fluid. For the toluene single phase flow, i.e. the liquid state and the superheated vapor, an approach for helically coiled tubes by 


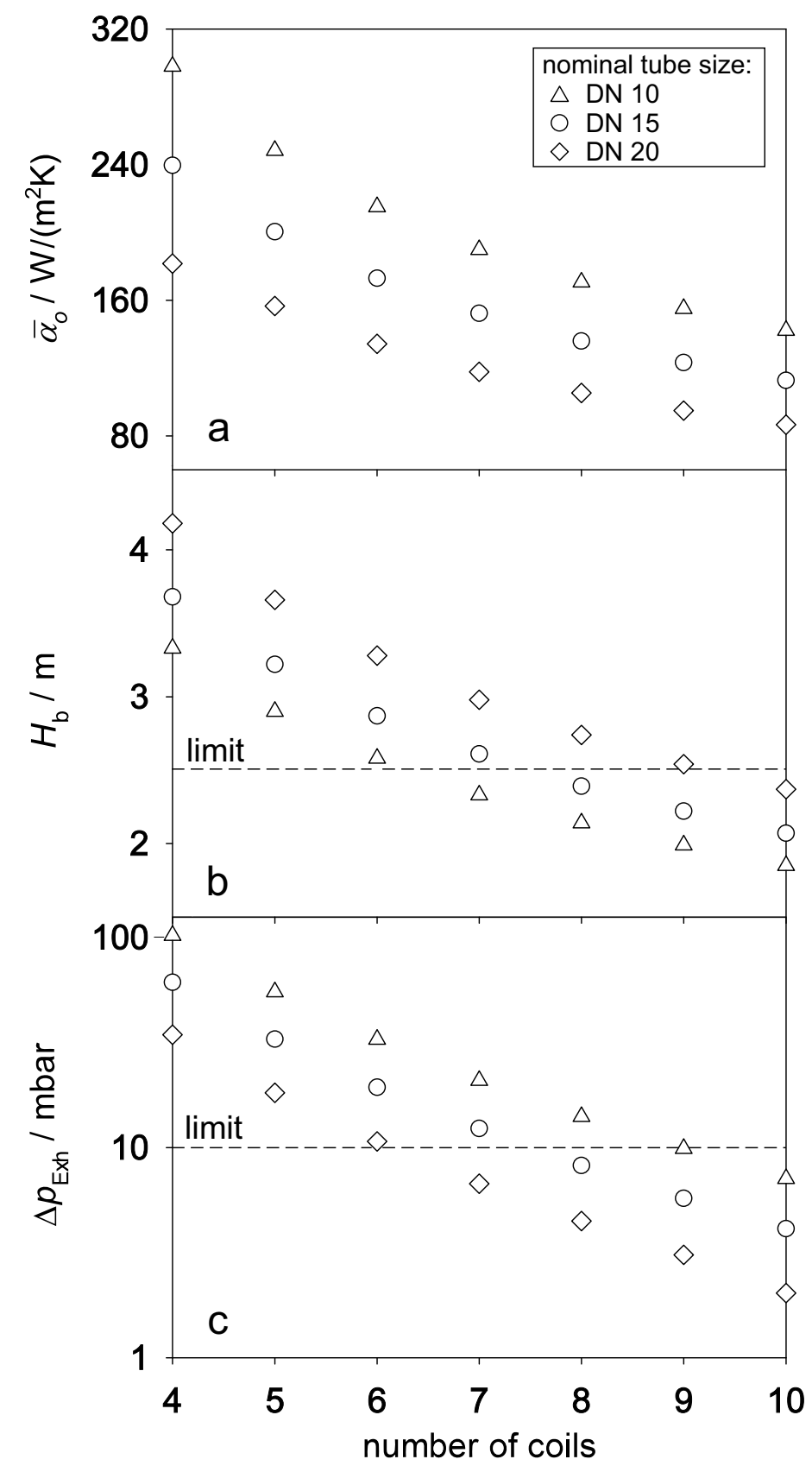

Figure 5: Selected results from the preliminary tube bundle design for different coil numbers and nominal tube sizes: a) averaged shell side heat transfer coefficient $\bar{\alpha}_{o}$; b) height of tube bundle $H_{\mathrm{b}} ; \mathrm{c}$ ) exhaust gas pressure loss $\Delta p_{\mathrm{Exh}}$. 
Gnielinski [40] was used, where the Nusselt number for turbulent flows with $\operatorname{Re}>2.2 \cdot 10^{4}$ is

$$
\mathrm{Nu}=\frac{\zeta / 8 \operatorname{Re} \operatorname{Pr}}{1+12.7 \sqrt{\zeta / 8}\left(\operatorname{Pr}^{2 / 3}-1\right)}\left(\frac{\operatorname{Pr}}{\operatorname{Pr}_{W}}\right)^{0.14},
$$

with the friction factor

$$
\zeta=\frac{0.3164}{\operatorname{Re}^{0.25}}+0.03\left(\frac{d_{i}}{D}\right)^{0.5},
$$

where $D$ is the diameter of the coil in an inclined plane, considering the coil diameter $D_{C}$ and the pitch $P$, cf. Fig. 3

$$
D=D_{C}\left(1+\left(\frac{P}{\pi D_{C}}\right)\right) .
$$

Subsequently, the heat transfer coefficient was calculated with $\alpha_{i}=\mathrm{Nu} \lambda / d_{i}$.

The pressure loss of a fluid at a single phase flow within a coiled tube can be determined following Gnielinski [40] and Mishra et al. [41]

$$
\Delta p_{\mathrm{WF}, \mathrm{sp}}=\zeta_{\mathrm{sp}} \frac{l}{d_{i}} \frac{\rho w_{i}^{2}}{2},
$$

with the tube length $l$ and the friction factor for turbulent flows

$$
\zeta_{\mathrm{sp}}=\frac{0.3164}{\operatorname{Re}^{0.25}}\left(1+0.095\left(\frac{d_{i}}{D}\right)^{0.5} \operatorname{Re}^{0.25}\right) .
$$

The two phase vapor-liquid flow in helical coiled tubes is complex and only few correlations to describe the heat transfer and pressure drop are available in the literature. Further, Kaya et al. [14] showed that the deviation between results determined with different correlations is large. Vashisth et al. [42] reviewed available research on flow phenomena within coiled tubes. They found that the flow patterns can approximately be described with the Lockhart-Martinelli parameter, used for the design of heat exchangers with straight horizontal tubes. Subsequently, the heat transfer coefficient inside the coils was calculated with an approach for flow boiling in horizontal tubes, described in the VDI Wärmeatlas [43] 


$$
\alpha_{i}=C_{\mathrm{F}}\left(\frac{\dot{q}}{\dot{q}_{0}}\right)^{n} F\left(p^{*}\right) F(d) F(W) F(\dot{M}, \dot{x}) \alpha_{0},
$$

where the parameters $C_{\mathrm{F}}, F\left(p^{*}\right), F(d)$ and $F(W)$ consider the influence of fluid properties, pressure, tube diameter and tube surface, respectively. The heat flux and the normalized heat flux were taken into account by $\dot{q}$ and $\dot{q}_{0}$. Further, the factor $F(\dot{M}, \dot{x})$ characterizes the flow pattern, including the mass flux $\dot{M}$ and the vapor quality $\dot{x}$, while $\alpha_{0}$ is the heat transfer coefficient at normalized conditions, given in the literature. The detailed estimation of these parameters is described in the Appendix. The pressure drop of the working fluid, caused by the two phase flow, was determined following Garcia et al. [44]

$$
\Delta p_{\mathrm{WF}, \mathrm{tp}}=2 \zeta_{\mathrm{tp}} \frac{l}{d_{i}} \rho w_{i}^{2},
$$

with the friction factor

$$
\zeta_{\text {tp }}=A_{2} \operatorname{Re}^{B 2}+\frac{A_{1} \operatorname{Re}^{B 1}-A_{2} \operatorname{Re}^{B 2}}{\left(1+(\operatorname{Re} / T)^{C}\right)^{D}},
$$

where the parameters $A_{1}, A_{2}, B_{1}, B_{2}, C, D$ and $T$ depend on the particular flow pattern and empirical values were available in the literature. The detailed calculation procedure including the determination of the flow pattern with the Lockhart-Martinelli parameter is described in the Appendix.

The design procedure based on a discretization of the heat exchanger and the LMTD method was extended with the correlations for the inside of the tubes. In a first step, the mean temperature of the working fluid in a segment was determined from the inlet and outlet conditions known from the preliminary design, leading to the averaged thermodynamic properties and to an inside heat transfer coefficient. The latter was used to substitute the preliminary value of $\alpha_{\mathrm{i}}=1000 \mathrm{~W} /\left(\mathrm{m}^{2} \mathrm{~K}\right)$. Subsequently, a recalculation of the heat transfer coefficient at the shell side was conducted, which in turn, led to new heat transfer coefficient inside the tube. In this way, an iterative approximation was carried out until the heat transfer coefficients were constant on both sides. Based on the proportion of the heat transfer surface, the mass flow rate of the working fluid in each coil was initially specified. After calculating all segments, the mass flow rates in the coils were adjusted so that an equal outlet temperature was reached. The pressure drop of the 
working fluid was determined for each segment and led to the total pressure drop by summarizing. Since the tube coil with the largest diameter leads to the highest pressure drop due to its largest tube length and mass flow rate, it was assumed that this value represents the pressure drop of the working fluid caused by the evaporator. This was permissible because the pressure within the inner coils was reduced by valves at the entry of the coils.

The resulting design parameters and obtained performances of the possible tube bundle configurations are summarized in Tab. 4. In general, the heat transfer that can be assessed by the overall heat transfer coefficient $k$ was minimal in the preheating section, increased at the evaporator and decreased at the superheater again. In association with a small logarithmic mean temperature difference $\Delta T_{\text {ln }}$ during preheating (cf. Fig. 2), the heat flux was low, which required a large heat transfer area and the major part of the total tube bundle height for this section of the heat exchanger. Evaporation and superheating of the working fluid takes place in a comparatively small part of the tube bundle, caused by increasing values of the overall heat transfer coefficient and $\Delta T_{\mathrm{ln}}$. Furthermore, it was ascertained that the tube bundle configurations with the smaller nominal tube size of DN 10 and especially with 9 coils, exhibit higher heat transfer coefficients at the tube inside, which can be explained by a higher mass flux of the working fluid. However, it was found that the crucial parameter resulting from the design calculation was the pressure drop of the working fluid. High flow velocities, which are advantageous for the heat transfer, also lead to high pressure loss, especially for configurations with the small tube diameter of DN 10 that are 1.10 and 0.92 bar for the tube bundles with 9 and 10 coils, respectively. The configuration with a nominal tube size of DN 15 and 8 coils yielded a pressure drop of 0.35 bar, which was suitable for the planned ORC plant. Since the other results obtained for this configuration, particularly the total tube bundle height of $2.29 \mathrm{~m}$ and the exhaust gas pressure drop of 9 mbar, were also within the specified limits, it was decided to realize the direct evaporator with this design.

Fig. 6 shows the heat transfer coefficients inside and outside the tubes, as well as the working fluid pressure drop as a function of the height of the selected tube bundle. The heat transfer coefficient on the shell side was highest at the exhaust gas entry with a value of $149 \mathrm{~W} /\left(\mathrm{m}^{2} \mathrm{~K}\right)$ and decreased to a value of $129 \mathrm{~W} /\left(\mathrm{m}^{2} \mathrm{~K}\right)$ at the exit, caused by the increasing density of the gas mixture during its cooling and the correlating decline of flow velocity. The mass flux of the working fluid inside the tubes was in a range of 201 to 
$395 \mathrm{~kg} /\left(\mathrm{m}^{2} \mathrm{~s}\right)$ at the inside and outside coil, respectively. Subsequently, the heat transfer coefficient inside the tubes was averaged over the eight coils and was lowest at the entry of the working fluid with a value of $1140 \mathrm{~W} /\left(\mathrm{m}^{2} \mathrm{~K}\right)$. With rising temperature and the related decrease in density, the flow velocity increased, leading to an increase of $\bar{\alpha}_{i}$ that had a value of $1464 \mathrm{~W} /\left(\mathrm{m}^{2} \mathrm{~K}\right)$ at the end of the preheating section. For the evaporation section, the two phase flow led to a rapid rise of the heat transfer coefficient with a value of 3510 $\mathrm{W} /\left(\mathrm{m}^{2} \mathrm{~K}\right)$ that also increased with further heating due to the increasing heat flux and flow velocity. The initial slug flow pattern subsequently changed into an annular flow pattern and thus to a further increase of $\bar{\alpha}_{i}$ that had its maximum value of $4546 \mathrm{~W} / \mathrm{m}^{2} \mathrm{~K}$ at a vapor quality of 0.55 . Further increase of the vapor quality led to a decrease of the heat transfer coefficient inside the tubes. With a single phase flow in the superheating section, the heat transfer coefficient declined again to a value of $1659 \mathrm{~W} /\left(\mathrm{m}^{2} \mathrm{~K}\right)$. The working fluid pressure loss as a function of the tube bundle height was approximately linear for the preheating section and had a value of 0.15 bar at a height of $1.58 \mathrm{~m}$. With the emergence of evaporation and the associated high velocity of the vapor-liquid flow, the pressure loss grows exponentially so that the major pressure drop of the working fluid was attained within the evaporation zone. Finally, it is worth to mention that $69 \%$ of the heat transfer area was needed for the preheating of the working fluid, while only $50 \%$ of the total heat flow was transferred in this section of the present heat exchanger.

\section{Description of field test}

The direct evaporator was manufactured with parameters close to the design calculations. For practical reasons, the spacing between the tube coils was slightly larger and with this the free shell annulus that had a cross section area of $0.3904 \mathrm{~m}^{2}$. The outside and inside diameters of the DN 15 tubes were $d_{o}=21.3 \mathrm{~mm}$ and $d_{i}=17.3 \mathrm{~mm}$, respectively, while the realized geometric parameters of the tube bundle were $a=2.347$ and $b=0.986$, with a total height of $2.5 \mathrm{~m}$ instead of $2.29 \mathrm{~m}$, to consider the uncertainties of the heat transfer correlations and to ensure a reliable operation of the planned ORC plant. A technical drawing and a photograph of the heat exchanger at the test site is shown in Fig. 7. The tube bundle was held by three mounting sheets that were manufactured stepwise with assembling the coils one after another from the inside to the outside. However, the tubes were not fixed with the mounting and free spacing was provided in order to avoid tensions 
Table 4: Results from the design calculation for different tube bundle configurations.

\begin{tabular}{|c|c|c|c|c|}
\hline Parameters & $\begin{array}{l}\text { DN } 15 \\
8 \text { coils }\end{array}$ & $\begin{array}{l}\text { DN } 10 \\
9 \text { coils }\end{array}$ & $\begin{array}{l}\text { DN } 10 \\
10 \text { coils }\end{array}$ & Unit \\
\hline \multicolumn{5}{|l|}{ Preheater } \\
\hline $\bar{\alpha}_{o}$ & 134 & 152 & 139 & $\mathrm{~W} /\left(\mathrm{m}^{2} \mathrm{~K}\right)$ \\
\hline $\bar{\alpha}_{i}$ & 1296 & 1889 & 1618 & $\mathrm{~W} /\left(\mathrm{m}^{2} \mathrm{~K}\right)$ \\
\hline $\bar{k}$ & 129 & 153 & 139 & $\mathrm{~W} /\left(\mathrm{m}^{2} \mathrm{~K}\right)$ \\
\hline$\Delta p_{\mathrm{WF}}$ & 0.145 & 0.377 & 0.321 & bar \\
\hline$\Delta p_{\text {Exh }}$ & 5.4 & 6.2 & 4.6 & mbar \\
\hline Height & 1.58 & 1.24 & 1.18 & $\mathrm{~m}$ \\
\hline \multicolumn{5}{|l|}{ Evaporator } \\
\hline $\bar{\alpha}_{o}$ & 142 & 161 & 148 & $\mathrm{~W} /\left(\mathrm{m}^{2} \mathrm{~K}\right)$ \\
\hline $\bar{\alpha}_{i}$ & 4064 & 5535 & 5260 & $\mathrm{~W} /\left(\mathrm{m}^{2} \mathrm{~K}\right)$ \\
\hline $\bar{k}$ & 147 & 172 & 159 & $\mathrm{~W} /\left(\mathrm{m}^{2} \mathrm{~K}\right)$ \\
\hline$\Delta p_{\mathrm{WF}}$ & 0.193 & 0.693 & 0.576 & bar \\
\hline$\Delta p_{\mathrm{Exh}}$ & 2.7 & 3.2 & 2.34 & mbar \\
\hline Height & 0.69 & 0.55 & 0.52 & $\mathrm{~m}$ \\
\hline \multicolumn{5}{|l|}{ Superheater } \\
\hline $\bar{\alpha}_{o}$ & 147 & 167 & 153 & $\mathrm{~W} /\left(\mathrm{m}^{2} \mathrm{~K}\right)$ \\
\hline $\bar{\alpha}_{i}$ & 1659 & 2379 & 1844 & $\mathrm{~W} /\left(\mathrm{m}^{2} \mathrm{~K}\right)$ \\
\hline $\bar{k}$ & 144 & 170 & 154 & $\mathrm{~W} /\left(\mathrm{m}^{2} \mathrm{~K}\right)$ \\
\hline$\Delta p_{\mathrm{WF}}$ & 0.015 & 0.025 & 0.022 & bar \\
\hline$\Delta p_{\text {Exh }}$ & 0.09 & 0.07 & 0.05 & mbar \\
\hline Height & 0.02 & 0.01 & 0.01 & $\mathrm{~m}$ \\
\hline Total height & 2.29 & 1.80 & 1.71 & $\mathrm{~m}$ \\
\hline Total tube length & 747 & 796 & 870 & $\mathrm{~m}$ \\
\hline Total $\Delta p_{\mathrm{WF}}$ & 0.353 & 1.095 & 0.919 & bar \\
\hline Total $\Delta p_{\text {Exh }}$ & 9 & 9.5 & 7 & mbar \\
\hline
\end{tabular}




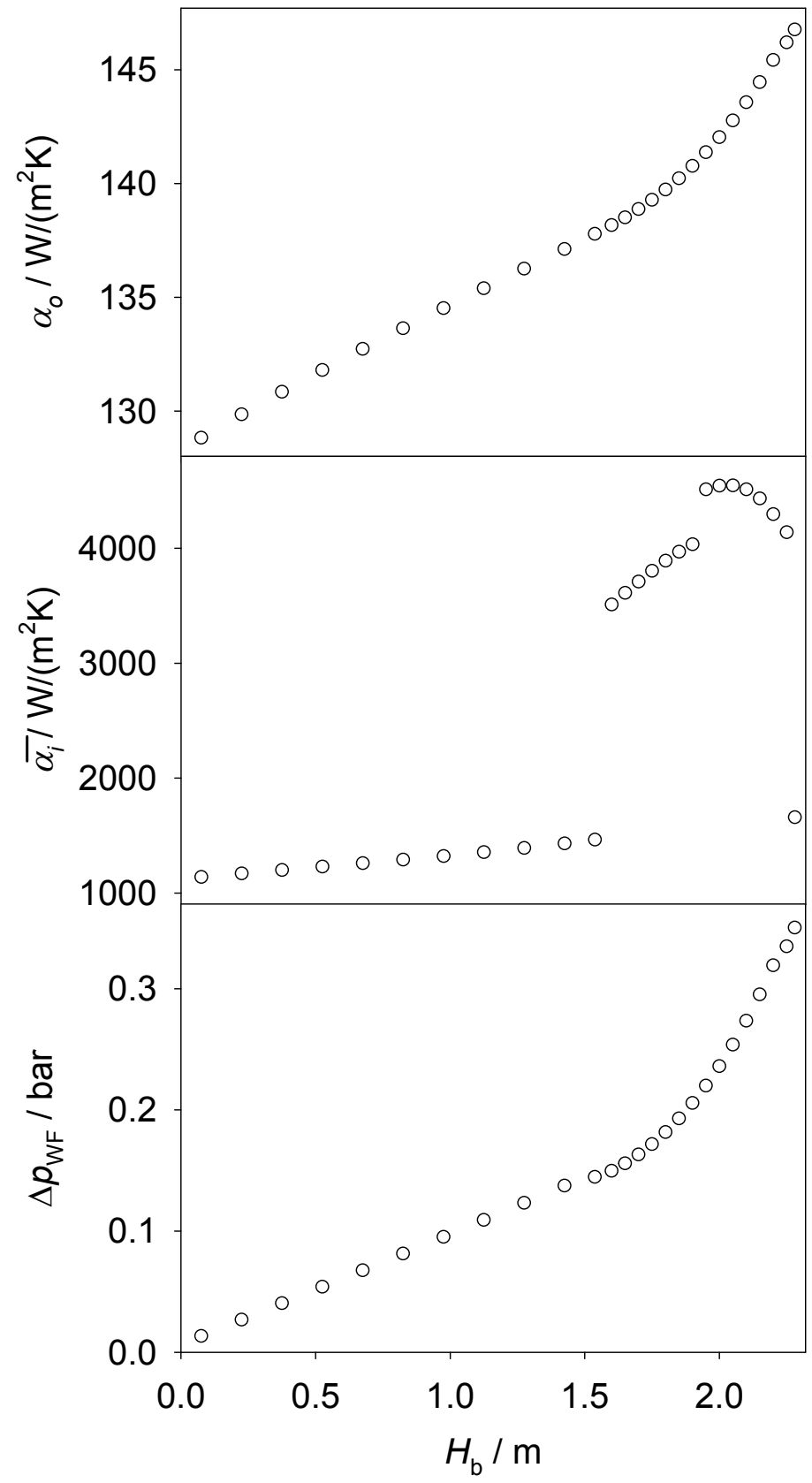

Figure 6: Heat transfer coefficient at the outside and inside of the tubes as well as the working fluid pressure drop as a function of tube bundle height for the selected design. 
caused by thermal expansion. The heat exchanger and the exhaust gas pipe were insulated with a $0.2 \mathrm{~m}$ thick layer of mineral wool and covered by a metal housing. The exhaust gas line of the CHP was adapted with a branch pipe in connection with a gas damper that allowed for a variable control of the exhaust flow provided to the evaporator. Further, the exhaust gas recirculation was driven by a fan that could be adjusted with a frequency inverter. Because of practical reasons only four valves were installed in front of the tube bundle, thus, the working fluid flow rate of two adjacent coils was adjusted by one motorized control valve.

The arrangement of the measuring instrumentation is illustrated in Fig. 1. All temperatures were measured with platinum resistance thermometers with a basic resistance of $1000 \Omega$ (Pt1000), while pressure measurement of the working fluid cycle was conducted with absolute pressure transmitters (APT) S-20 supplied by WIKA. For the determination of the mass flow rate in the ORC, a differential pressure flow meter according to DIN EN ISO 5167 was used, equipped with a differential pressure transmitter DE 70 by Fischer. Further, a pitot static tube anemometer combined with a C 310 multifunctional transmitter by KIMO was used for the measurement of the exhaust gas flow ratio. The difference pressure module of the $\mathrm{C} 310$ transmitter was also employed to determine the pressure drop on the shell side of the heat exchanger. The uncertainties of the measuring equipment are given in Tab. 5 .

The evaluation and tests of the direct evaporator were conducted while the ORC test rig was not entirely completed. Especially the turbine was not operational, thus, the working fluid was carried through a bypass (cf. Fig. 1) and expanded with an orifice plate, before entering the recuperator. To reach the nominal mass flow rate, the orifice plate was designed with a cross-sectional area that was $64 \%$ larger than the minimum cross-sectional area of the turbine nozzle, considering the coefficient of contraction [43]. For the experiments, first, the cooling cycle was started, followed by the working fluid feed pump, beginning with a low rotational frequency and a slight opening of the exhaust gas damper. Subsequently, the flow rates of toluene and exhaust gas were increased stepwise, while the fan of the exhaust recirculation was adjusted in line to obtain a target state point. The start up of the experimental setup took about $30 \mathrm{~min}$ and when a steady state in terms of constant mass flow rates, temperatures and pressures was reached, the measured parameters were used to evaluate the performance of the heat exchanger. 




Figure 7: Left: Technical drawing of the direct evaporator, with hidden tube bundle for better clarity. Right: Photograph of the apparatus at the test site.

Table 5: Uncertainties of the measuring equipment.

\begin{tabular}{llll}
\hline Variable & Sensor type & Range & Uncertainty \\
\hline$T$ (exhaust) & Pt1000 & $0-480^{\circ} \mathrm{C}$ & $\pm 0.10 \%$ \\
$T$ (ORC) & Pt1000 & $0-350^{\circ} \mathrm{C}$ & $\pm 0.10 \%$ \\
$p$ (ORC high pressure $)$ & APT & $0-25 \mathrm{bar}$ & $\leq \pm 0.5 \%$ \\
$p$ (ORC low pressure) & APT & $0-6 \mathrm{bar}$ & $\leq \pm 0.5 \%$ \\
$\dot{m}$ (ORC) & difference pressure & $0.22-0.707 \mathrm{~kg} / \mathrm{s}$ & $\pm 1.4 \%$ \\
$\dot{m}$ (exhaust) & Pitot static tube & $0-2.2 \mathrm{~kg} / \mathrm{s}$ & $\pm 1.2 \%$ \\
$\Delta p$ (exhaust) & difference pressure & $0-1000 \mathrm{~Pa}$ & $\pm 0.2 \%$ \\
\hline
\end{tabular}




\section{Results and discussion}

\subsection{Heat transfer performance}

The heat transfer performance of the present direct evaporator was investigated under different operating conditions. The working fluid mass flow rate was varied between 0.45 and $0.54 \mathrm{~kg} / \mathrm{s}$, the inlet temperature and pressure was between 175 and $205.5^{\circ} \mathrm{C}$ and 14.1 and 19.7 bar, respectively, while the degree of superheating ranged between 6.2 and $30.7 \mathrm{~K}$. The mass flow rate of the exhaust gas was between 1.15 and $1.3 \mathrm{~kg} / \mathrm{s}$, with inlet temperatures varying from 348 to $394^{\circ} \mathrm{C}$. The maximum heat flow transferred to the toluene was $225 \mathrm{~kW}$. To evaluate the experimental data, the overall heat transfer coefficient $k$ (cf. Eq. (4)) was recalculated with the known heat transfer area and heat flow, while the logarithmic mean temperature difference was determined for the preheater, evaporator and superheater sections, respectively. This was conducted with the knowledge of the working fluid saturation temperature that led to the pinch point temperature difference. Subsequently, the overall heat transfer coefficient from experiment was compared with the correlations presented in section 2.3.

The results are shown in Fig. 8 and it can be stated that the experimental values of $k$, being in a range between 100.1 and $118.1 \mathrm{~W} /\left(\mathrm{m}^{2} \mathrm{~K}\right)$, are in good agreement with those from the correlations with a maximum relative deviation of $5.2 \%$ and an averaged deviation of $2 \%$. Moreover, it can be seen that the overall heat transfer coefficient recalculated from the experimental data tends to be lower than that from the correlations. In a further step, the Nusselt number on the shell side was recalculated from the experimental values of $k$ to examine the convective heat transfer between the exhaust gas and the tube bundle that represents the main heat transfer resistance. For this purpose, the heat transfer coefficient inside the tubes was obtained from the correlations, which is sufficiently accurate because of the small influence of $\alpha_{i}$ on $k$. The resulting tube bundle Nusselt numbers from present experiments and from the Gnielinski correlation are shown in Fig. 9 as a function of the Reynolds number. Because of the connection between the overall heat transfer coefficient and the Nusselt number, the relative deviation between the experimental results and those from the correlation is similar and in a range of up to $5.5 \%$, with an averaged value of $2.2 \%$. However, it can be seen that the experimental results tend to be higher than the predicted data at small Reynolds numbers and lower at higher Reynolds numbers. The slope of the Nusselt number correlation as a function of the Reynolds number seems 
to be slightly too high for the present heat exchanger.

In general, it turned out that the employed heat transfer correlations are suitable for the design of a direct evaporator with multiple helical coils. The overall heat transfer coefficient, recalculated from the measurements, was lower than that obtained in the original design calculation in section 2.3, which can be explained by the slightly different geometry parameters of the manufactured tube bundle. However, the target heat flow transferred to the working fluid of $263 \mathrm{~kW}$ was not reached yet, since it was not possible to achieve the nominal operating condition without a turbine. Once the turbine will be in operation, higher working fluid mass flow rates should be possible and consequently the exhaust gas mass flow rate can be increased as well. Then, the toluene will enter the evaporator at a lower temperature because of a decreasing heat flow in the recuperator. Based on these aspects and by considering the observations from the present work, it can be expected that the desired heat flow will be reached because of increasing heat transfer coefficients and a larger logarithmic temperature difference between exhaust gas and toluene.

Another focus was on the working fluid temperature at the exit of each coil, where the variation was supposed to be small. For this reason, the mass flow rate within two adjacent coils was adjusted by a valve in front of these coils, respectively. It was observed that this setup is operational, but a notable temperature difference occurs for a pair of coils, where the inner coil is only slightly superheated, while the outer coil with the larger heat transfer area, was superheated in a range between 25 to $30 \mathrm{~K}$. The required vapor temperature was then reached after mixing of the individual vapor flows. It has to be noted that a high degree of superheating in the tube coils will cause a reduction in the working fluid lifetime. Thus, an adjustable valve in front of each coil is suggested, while it can be stated that a heat exchanger with multiple helical coils and without any regulation of the mass flow inside the tubes, as discussed by Wang et al. [22], cannot be operational in terms of an appropriate vapor quality. In addition, the heat loss of the present heat exchanger was determined to be in a range of 2.5 to $14.2 \%$ of the exhaust gas heat flow, with an averaged value of $7.1 \%$. Thus, the heat loss is higher than expected, which could be a consequence of a humid mineral wool insulation, unfortunately caused by rain that leaked through the metal housing. 


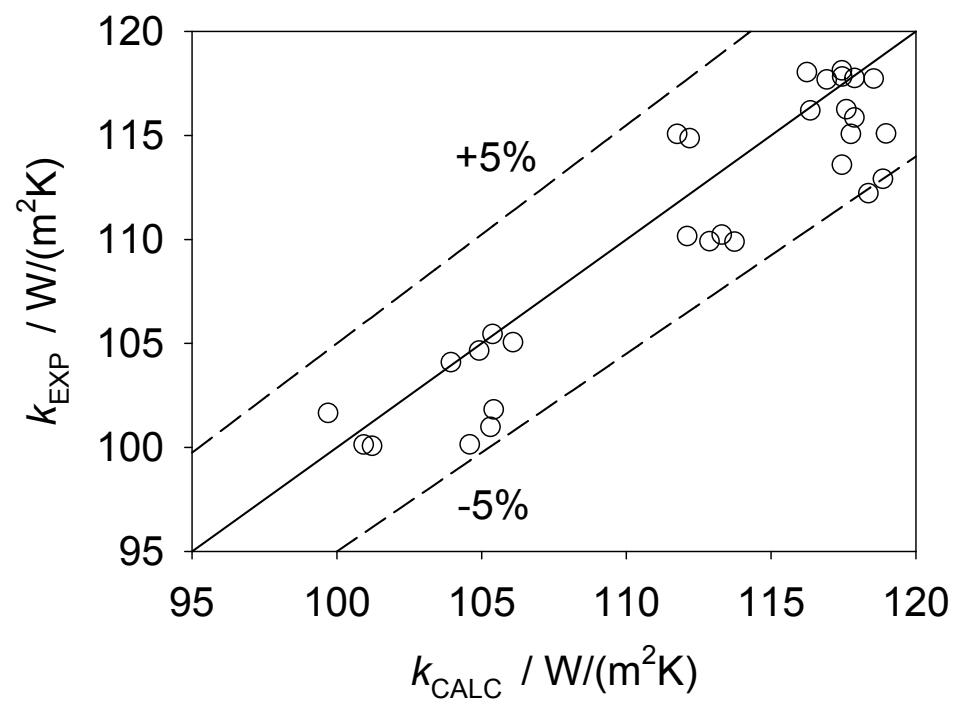

Figure 8: Overall heat transfer coefficient from experiment compared with predicted values.



Figure 9: Shell side Nusselt number as a function of Reynolds number from experiment (o) compared with predicted values (-). 


\subsection{Pressure loss}

To ensure an unrestricted operation of the CHP, the exhaust gas pressure loss of the direct evaporator was measured for different mass flow rates in a range from 0.56 to $1.36 \mathrm{~kg} / \mathrm{s}$ and compared with the values predicted with the approach of Gaddis and Gnielinski, cf. section 2.3. The correlation was used to calculate the pressure loss depending on the characteristic exhaust flow velocity and for three temperatures of 130,255 and $380^{\circ} \mathrm{C}$. The averaged exhaust temperatures during the experiments were within this range and the results are shown in Fig. 10, with a measured pressure loss from 141 to $900 \mathrm{~Pa}$ and a flow velocity in a range between 3.5 and $10.9 \mathrm{~m} / \mathrm{s}$. These values agree well with the correlation, but tend to be slightly higher, the relative deviation is between 1.8 and $6.9 \%$. It can be seen that the pressure drop increases quadratically with increasing flow velocity and increases with decreasing temperature. Additionally, the shell side pressure loss coefficient was recalculated from the experimental data, which is particularly suitable to validate the employed correlation for the design of the present apparatus because the dominating variable is the Reynolds number, while the temperature influence is small. The experimental pressure loss coefficient for Reynolds numbers in a range of 2186 to 6431 is compared with the correlation values at temperatures of 130,255 and $380^{\circ} \mathrm{C}$ in Fig. 11. It turns out that the pressure loss coefficient, recalculated from experiments, is higher than the predicted value and that the maximum deviation of $6.9 \%$ occurs at the lowest Reynolds number, while there is better agreement with increasing Reynolds number. Considering the fact that the experiments were carried out with an exhaust gas flow in the laminar-turbulent transition zone (100 $<\operatorname{Re}<10^{4}$ ), the correlation seems to underestimate the influence of the laminar flow for the tube bundle design of the present work. However, the prediction of the shell side pressure loss was satisfactory, especially near the nominal operating condition and it can be stated that the required limit of 10 mbar was not exceeded.

For the working fluid toluene, pressure drop values between 0.5 and 1.1 bar were measured, which was higher than expected. The interpretation of these results to validate the employed tube side pressure loss correlations is difficult because the pressure transducers were not located directly in front and behind the exit of the tube bundle, respectively, but after the recuperator and in front of the turbine. Consequently, the pressure loss caused by the piping and the adjustable valves in front of the tube bundle was included in the measurements. Especially mixing and redirection of the vapor flow after 
the tube bundle could have caused a significant pressure loss. Furthermore, the difference in the degree of superheating at the exit of two adjacent coils, which was not considered during the design process, did not allow for an accurate comparison between the predicted values from the correlation and the experimental results. For the present ORC test rig, the feed pump allowed to compensate the working fluid pressure loss by increasing the rotational frequency. By this measure, it was possible to reach the target state point after the heat exchanger, which is of key importance to operate the turbine at its maximum efficiency.



Figure 10: Exhaust pressure drop as a function of the characteristic flow velocity from experiment (symbols) and correlation (lines) for different temperatures.

\section{Conclusion}

A direct evaporator of shell and multi helical coils type for a high temperature ORC plant to exploit exhaust waste heat was designed and tested. The requirements and boundary limits for the heat exchanger, the employed heat transfer and pressure loss correlations from the literature, the influence of the different parameters and the procedure to find an optimal design were presented. It was found that the main heat resistance is on the shell side, 


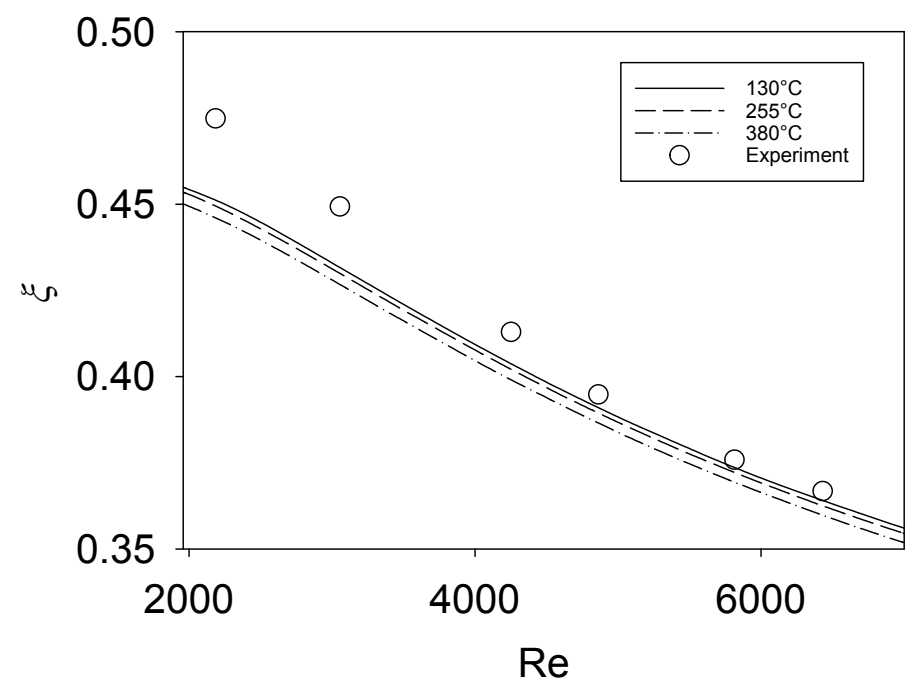

Figure 11: Shell side pressure loss coefficient as a function of Reynolds number from experiment (o) and correlation (lines).

flown through by the exhaust gas and that its maximum permissible pressure loss is the limiting factor for the heat transfer coefficient. Subsequently, the direct evaporator with a tube bundle consisting of eight coils was manufactured and connected to an ORC plant that used toluene as a working fluid. Tests under various operating conditions were carried out, allowing for the determination of the overall heat transfer coefficient and shell side Nusselt number that were compared with the results from correlations. The experimental data were in good agreement with a deviation less than $5.5 \%$, but tended to be slightly lower than the predicted values. Measurements of the shell side pressure drop were in good agreement, but slightly higher than the predicted data. It was found that the employed pressure loss correlation underestimates the influence of the laminar flow at low Reynolds numbers for the tube bundle design of the present work. Furthermore, it was essential to regulate the mass flow rate of the working fluid in front of each coil with adjustable valves to achieve a regular vapor quality. It can be concluded that the employed correlations and the optimization method are suitable for the design of a shell and helical coils evaporator. The test apparatus had a reliable operational behavior at a maximum transferred heat flow of $225 \mathrm{~kW}$ and was particularly qualified for the test site due to its compactness. 


$$
\xi_{\mathrm{t}}=2.5+\left(\frac{1.2}{(a-0.85)^{1.08}}\right)+0.4\left(\frac{b}{a}-1\right)^{3}-0.01\left(\frac{a}{b}-1\right)^{3} \operatorname{Re}_{n}^{-0.25}
$$

and a turbulent part with 
where the factor $F_{\mathrm{v}}$ is

$$
F_{\mathrm{v}}=1-\exp \left(-\frac{\operatorname{Re}_{n}+200}{1000}\right) .
$$

635

and

$$
f_{\mathrm{z}, \mathrm{t}}=\left(\frac{\eta_{W}}{\eta_{m}}\right)^{0.14},
$$

$$
F\left(p^{*}\right)=2.692 p^{* 0.43}+\frac{1.6 p^{* 6.5}}{1-p^{* 4.4}},
$$

${ }_{646}$ where the reduced pressure is $p^{*}=p_{s} / p_{c}$. Further, the tube dimension factor 647 is

$$
F(d)=\left(0.01 \mathrm{~m} / d_{i}\right)^{0.5},
$$

648 and the wall surface influence is

$$
F(W)=\left(R_{a} / R_{a 0}\right)^{0.133}
$$


with the arithmetic average roughness $R_{a}$ and the normalized value $R_{a 0}$ that was $1 \mu \mathrm{m}$. The flow pattern factor in dependence of the mass flux $\dot{M}$ and the vapor quality $\dot{x}$ was considered by

$$
F(\dot{M}, \dot{x})=\left(\frac{\dot{M}}{\dot{M}_{0}}\right)^{0.25}\left(1-p^{* 0.1}\left(\frac{\dot{q}}{\dot{q}_{\mathrm{cr}, \mathrm{PB}}}\right)^{0.3} \dot{x}\right),
$$

where $\dot{M}_{0}$ is the normalized mass flux with a value of $100 \mathrm{~kg} /\left(\mathrm{m}^{2} \mathrm{~s}\right)$ and $\dot{q}_{\mathrm{cr}, \mathrm{PB}}$ is a reference heat flux

$$
\dot{q}_{\mathrm{cr}, \mathrm{PB}}=3.2 p^{* 0.45}\left(1-p^{*}\right)^{1.2} \dot{q}_{\mathrm{cr}, 0.1}, \quad \text { for } p^{*} \geq 0.1,
$$

and the critical heat flux for the case $p^{*}=0.1$ is

$$
\dot{q}_{\mathrm{cr}, 0.1}=0.144 \Delta h_{v}\left(\left(\rho^{\prime}-\rho^{\prime \prime}\right) \rho^{\prime \prime}\right)^{0.5}\left((g \sigma) / \rho^{\prime}\right)^{0.25} \operatorname{Pr}^{-0.245},
$$

where $\Delta h_{v}$ is the heat of vaporization, $\rho^{\prime}$ and $\rho^{\prime \prime}$ the saturated liquid and vapor density, respectively, $g$ the standard gravity constant and $\sigma$ the surface tension. Further, the normalized heat transfer coefficient and heat flux were available in the literature with $\alpha_{0}=2910 \mathrm{~W} /\left(\mathrm{m}^{2} \mathrm{~K}\right)$ and $\dot{q}_{0}=20000 \mathrm{~W} / \mathrm{m}^{2}$ for toluene.

For the present case of employing a hydrocarbon and a low thermal conductivity of the wall material (product of wall thickness and its thermal conductivity $\lambda_{S} \cdot t \leq 0.7 \mathrm{~W} / \mathrm{K}$ ) the exponent $n$ has to be calculated with

$$
n=\kappa\left(0.9-0.36 p^{* 0.13}\right) \text {, }
$$

and

$$
\kappa=0.675+0.325 \tanh \left(3.711\left(\lambda_{S} \cdot t-0.0324\right)\right) .
$$

The influence of the fluid properties was calculated with

$$
C_{F^{*}}=0.789\left(\frac{M_{\mathrm{WF}}}{M_{\mathrm{H} 2}}\right)^{0.11},
$$

where $M_{\mathrm{WF}}$ and $M_{\mathrm{H} 2}$ are the molar masses of the working fluid and of hydrogen, respectively. This correlation is valid for $C_{F^{*}} \leq 2.5$. Due to $\lambda_{S} \cdot t \leq 0.7$ $\mathrm{W} / \mathrm{K}$, a correction for different flow patterns, has to be conducted and it is $C_{F}=\psi C_{F^{*}}$, with the correction factor 


$$
\psi=0.46+0.4 \tanh \left(3.387\left(\lambda_{S} \cdot t-0.00862\right)\right),
$$

669

for stratified or wavy flow patterns,

$$
\psi=0.671+0.329 \tanh \left(3.691\left(\lambda_{S} \cdot t-0.00842\right)\right)
$$

670

for slug flow patterns and

$$
\psi=0.755+0.245 \tanh \left(3.702\left(\lambda_{S} \cdot t-0.0125\right)\right),
$$

671

672

for annular flow patterns. The determination of the flow patterns is described in the following section.

Appendix A.3. Determination of two-phase flow patterns

The different flow patterns that occur at the vapor-liquid flow inside the tubes were determined with a method described in the VDI Wärmeatlas, where a flow pattern map that is based on the work of Taitel and Dukler [45] is used. Here, the main parameter is the Lockhart-Martinelli number

$$
X=\left(\frac{1-\dot{x}}{\dot{x}}\right)^{0.875}\left(\frac{\rho^{\prime \prime}}{\rho^{\prime}}\right)^{0.5}\left(\frac{\eta^{\prime \prime}}{\eta^{\prime}}\right)^{0.125},
$$

with the saturated liquid and vapor viscosity $\eta^{\prime}$ and $\eta^{\prime \prime}$, respectively. The limiting curves in the flow pattern map are defined by the following numbers

$$
\begin{gathered}
\left(\operatorname{Re}_{L} \mathrm{Fr}_{G}^{\prime}\right)^{0.5}=\left(\frac{\dot{M}^{3} \dot{x}^{2}(1-\dot{x})}{\rho^{\prime \prime}\left(\rho^{\prime}-\rho^{\prime \prime}\right) \eta^{\prime} g \cos \Theta}\right)^{0.5}, \\
\operatorname{Fr}_{G m}^{0.5}=\left(\frac{\dot{M}^{2} \dot{x}^{2}}{g d_{i} \rho^{\prime} \rho^{\prime \prime}}\right)^{0.5}, \\
(\mathrm{Fr} \mathrm{Eu})_{L}^{0.5}=\left(\frac{\xi^{\prime} \dot{M}^{2}(1-\dot{x})^{2}}{2 d_{i} \rho^{\prime}\left(\rho^{\prime}-\rho^{\prime \prime}\right) g \cos \Theta}\right)^{0.5}, \\
(\mathrm{We} / \mathrm{Fr})_{L}=\frac{g d_{i}^{2} \rho^{\prime}}{\sigma}
\end{gathered}
$$

following the notation of the VDI Wärmeatlas. The pitch angle of the tubes is considered by $\Theta$ and $\xi^{\prime}$ is the pressure loss coefficient with 


$$
\xi^{\prime}=\frac{0.3164}{\operatorname{Re}^{\prime 0.25}}
$$

682

with the Reynolds number of the liquid

$$
\operatorname{Re}^{\prime}=\frac{\dot{M}(1-\dot{x}) d_{i}}{\eta^{\prime}}
$$

\section{Appendix A.4. Two-phase flow pressure loss}

The vapor-liquid flow friction factor in the pressure loss correlation by Garcia et al. [44] was calculated with a Reynolds number that is

$$
\operatorname{Re}=\frac{w_{i} d_{i} \rho^{\prime}}{\eta^{\prime}}
$$

with the flow velocity

$$
w_{i}=w^{\prime}+w^{\prime \prime} .
$$

The employed parameters depending on the flow pattern are listed in Tab. A.6.

Table A.6: Parameters of the employed vapor-liquid pressure loss correlation by Garcia et al. [44].

\begin{tabular}{lccccccr}
\hline Parameters & A1 & A2 & B1 & B2 & C & D & \multicolumn{1}{c}{ T } \\
\hline Slug flow & 13.98 & 0.1067 & -0.9501 & -0.2629 & 3.577 & 0.2029 & 293 \\
Dispersed bubble flow & 13.98 & 0.1067 & -0.9501 & -0.2629 & 2.948 & 0.2236 & 304 \\
Stratified flow & 13.98 & 0.0445 & -0.9501 & -0.1874 & 9.275 & 0.0324 & 300 \\
Annular flow & 3.671 & 0.0270 & -0.6257 & -0.1225 & 2.191 & 0.2072 & 10000 \\
\hline
\end{tabular}

\section{References}

[1] Intergovernmental Panel on Climate Change, Fifth Assesment Report, 2013, Available from: http://www.ipcc.ch/ (accessed 11 March 2019).

[2] J. H. Seinfeld, S. N. Pandis, Atmospheric Chemistry and Physics: From Air Pollution to Climate Change, 2nd Edition, John Wiley \& Sons, Hoboken, NJ, 2012. 
[3] T.-C. Hung, T. Shai, S. K. Wang, A review of organic Rankine cycles (ORCs) for the recovery of low-grade waste heat, Energy 22 (1997) 661667. doi:10.1016/S0360-5442(96)00165-X.

[4] A. Desideri, S. Gusev, M. Van den Broek, V. Lemort, S. Quoilin, Experimental comparison of organic fluids for low temperature ORC (organic Rankine cycle) systems for waste heat recovery applications, Energy 97 (2016) 460-469. doi:10.1016/j.energy.2015.12.012.

[5] E. Barbier, Nature and technology of geothermal energy: A review, Renewable and Sustainable Energy Reviews 1 (1997) 1-69. doi:10.1016/S1364-0321(97)00001-4.

[6] S. Quoilin, M. Orosz, H. Hemond, V. Lemort, Performance and design optimization of a low-cost solar organic Rankine cycle for remote power generation, Solar Energy 85 (2011) 955-966. doi:10.1016/j.solener.2011.02.010.

[7] G. Qiu, Y. Shao, J. Li, H. Liu, S. B. Riffat, Experimental investigation of a biomass-fired ORC-based micro-CHP for domestic applications, Fuel 96 (2012) 374-382. doi:10.1016/j.fuel.2012.01.028.

[8] J. Larjola, Electricity from industrial waste heat using high-speed organic Rankine cycle (ORC), International Journal of Production Economics 41 (1995) 227-235. doi:10.1016/0925-5273(94)00098-0.

[9] P. Colonna, E. Casati, C. Trapp, T. Mathijssen, J. Larjola, T. TurunenSaaresti, A. Uusitalo, Organic Rankine Cycle Power Systems: From the Concept to Current Technology, Applications, and an Outlook to the Future, Journal of Engineering for Gas Turbines and Power 137 (2015) 100801. doi:10.1115/1.4029884.

[10] S. Quoilin, M. Van Den Broek, S. Declaye, P. Dewallef, V. Lemort, Techno-economic survey of Organic Rankine Cycle (ORC) systems, Renewable and Sustainable Energy Reviews 22 (2013) 168-186. doi:10.1016/j.rser.2013.01.028.

[11] J. Bao, L. Zhao, A review of working fluid and expander selections for organic Rankine cycle, Renewable and Sustainable Energy Reviews 24 (2013) 325-342. doi:10.1016/j.rser.2013.03.040. 
[12] B. F. Tchanche, G. Lambrinos, A. Frangoudakis, G. Papadakis, Lowgrade heat conversion into power using organic Rankine cycles - A review of various applications, Renewable and Sustainable Energy Reviews 15 (2011) 3963-3979. doi:10.1016/j.rser.2011.07.024.

[13] S. Lecompte, H. Huisseune, M. Van Den Broek, B. Vanslambrouck, M. De Paepe, Review of organic Rankine cycle (ORC) architectures for waste heat recovery, Renewable and Sustainable Energy Reviews 47 (2015) 448-461. doi:10.1016/j.rser.2015.03.089.

[14] A. Kaya, M. Lazova, G. Kosmadakis, S. Lecompte, M. D. Paepe, Evaluation of Existing Heat Transfer Correlations in Designing Helical Coil Evaporators for Low-Temperature Organic Rankine Cycles via Inverse Design Approach, Heat Transfer Engineering, in press (2018). doi:10.1080/01457632.2018.1457250.

[15] F. H. Dubberke, M. Linnemann, W. K. Abbas, E. Baumhögger, K.P. Priebe, M. Roedder, M. Neef, J. Vrabec, Experimental setup of a cascaded two-stage organic Rankine cycle, Applied Thermal Engineering 131 (2018) 958-964. doi:10.1016/j.applthermaleng.2017.11.137.

[16] M. Preißinger, D. Brüggemann, Thermal stability of hexamethyldisiloxane (MM) for high-temperature organic Rankine cycle (ORC), Energies 9 (2016) 183. doi:10.3390/en9030183.

[17] F. Yang, H. Zhang, C. Bei, S. Song, E. Wang, Parametric optimization and performance analysis of ORC (organic Rankine cycle) for diesel engine waste heat recovery with a fin-and-tube evaporator, Energy 91 (2015) 128-141. doi:10.1016/j.energy.2015.08.034.

[18] M. K. Jensen, Boiling heat transfer and critical heat flux in helical coils, $\mathrm{PhD}$ thesis, Iowa State University, Ames, 1980.

[19] D. Prabhanjan, G. Raghavan, T. Rennie, Comparison of heat transfer rates between a straight tube heat exchanger and a helically coiled heat exchanger, International Communications in Heat and Mass Transfer 29 (2002) 185-191. doi:10.1016/S0735-1933(02)00309-3.

[20] G. Kosmadakis, A. Landelle, M. Lazova, D. Manolakos, A. Kaya, H. Huisseune, C.-S. Karavas, N. Tauveron, R. Revellin, P. Haber- 
schill, et al., Experimental testing of a low-temperature organic Rankine cycle (ORC) engine coupled with concentrating $\mathrm{PV} /$ thermal collectors: Laboratory and field tests, Energy 117 (2016) 222-236. doi:10.1016/j.energy.2016.10.047.

[21] M. Hatami, D. Ganji, M. Gorji-Bandpy, A review of different heat exchangers designs for increasing the diesel exhaust waste heat recovery, Renewable and Sustainable Energy Reviews 37 (2014) 168-181. doi:10.1016/j.rser.2014.05.004.

[22] T. Wang, Y. Zhang, J. Zhang, G. Shu, Z. Peng, Analysis of recoverable exhaust energy from a light-duty gasoline engine, Applied Thermal Engineering 53 (2013) 414-419. doi:10.1016/j.applthermaleng.2012.03.025.

[23] Technical datasheet MWM TCG 2016 V16 C, Caterpillar Energy Solutions GmbH: Mannheim, Germany (2013).

[24] O. Kunz, W. Wagner, The GERG-2008 wide-range equation of state for natural gases and other mixtures: an expansion of GERG2004, Journal of Chemical \& Engineering Data 57 (2012) 3032-3091. doi:10.1021/je300655b.

[25] C. Wilke, A Viscosity Equation for Gas Mixtures, The Journal of Chemical Physics 18 (1950) 517-519. doi:10.1063/1.1747673.

[26] E. Mason, S. Saxena, Approximate Formula for the Thermal Conductivity of Gas Mixtures, Physics of Fluids 1 (1958) 361-369. doi:10.1063/1.1724352.

[27] A. Fenghour, W. A. Wakeham, V. Vesovic, The Viscosity of Carbon Dioxide, Journal of Physical and Chemical Reference Data 27 (1998) 31-44. doi:10.1063/1.556013.

[28] V. Vesovic, W. Wakeham, G. Olchowy, J. Sengers, J. Watson, J. Millat, The Transport Properties of Carbon Dioxide, Journal of Physical and Chemical Reference Data 19 (1990) 763-808. doi:10.1063/1.555875.

[29] E. W. Lemmon, R. Jacobsen, Viscosity and Thermal Conductivity Equations for Nitrogen, Oxygen, Argon, and Air, International Journal of Thermophysics 25 (2004) 21-69. doi:10.1023/B:IJOT.0000022327.04529.f3. 
[30] M. L. Huber, R. A. Perkins, A. Laesecke, D. G. Friend, J. V. Sengers, M. J. Assael, I. N. Metaxa, E. Vogel, R. Mareš, K. Miyagawa, New International Formulation for the Viscosity of H20, Journal of Physical and Chemical Reference Data 38 (2009) 101-125. doi:10.1063/1.3088050.

[31] M. L. Huber, R. A. Perkins, D. G. Friend, J. V. Sengers, M. J. Assael, I. N. Metaxa, K. Miyagawa, R. Hellmann, E. Vogel, New International Formulation for the Thermal Conductivity of H2O, Journal of Physical and Chemical Reference Data 41 (2012) 033102. doi:10.1063/1.4738955.

[32] Safety datasheet toluene, Version 1.5, Merck KGaA: Darmstadt, Germany (2017).

[33] W. C. Andersen, T. J. Bruno, Rapid Screening of Fluids for Chemical Stability in Organic Rankine Cycle Applications, Industrial \& Engineering Chemistry Research 44 (2005) 5560-5566. doi:10.1021/ie050351s.

[34] D. Kuhn, M. A. Kholiq, E. Heinzle, B. Bühler, A. Schmid, Intensification and economic and ecological assessment of a biocatalytic oxyfunctionalization process, Green Chemistry 12 (2010) 815-827. doi:10.1039/B921896C.

[35] H. D. Baehr, K. Stephan, Heat and Mass Transfer, Springer, Berlin, 2011. doi:10.1007/978-3-642-20021-2.

[36] M. Spittel, T. Spittel, Steel symbol/number: X6CrNiMoTi17-122/1.4571, in: Metal Forming Data of Ferrous Alloys-deformation behaviour, Springer, 2009, pp. 744-749.

[37] J. P. Gupta, Fundamentals of heat exchanger and pressure vessel technology, Hemisphere Publishing, NY, 1986.

[38] V. Gnielinski, Gleichungen zur Berechnung des Wärmeübergangs in querdurchströmten einzelnen Rohrreihen und Rohrbündeln, Forschung im Ingenieurwesen A 44 (1978) 15-25. doi:10.1007/BF02560750.

[39] E. S. Gaddis, V. Gnielinski, Pressure drop on the shell side of shell-and-tube heat exchangers with segmental baffles, Chemical Engineering and Processing: Process Intensification 36 (1997) 149-159. doi:10.1016/S0255-2701(96)04194-3. 
[40] V. Gnielinski, Heat transfer and pressure drop in helically coiled tubes, in: Proceedings 8th International Heat Transfer Conference, San Francisco CA, Hemisphere, Washington, DC, Vol. 6, 1986, pp. 2847-2854.

[41] P. Mishra, S. Gupta, Momentum transfer in curved pipes. 1. Newtonian fluids, Industrial \& Engineering Chemistry Process Design and Development 18 (1979) 130-137. doi:10.1021/i260069a017.

[42] S. Vashisth, V. Kumar, K. D. Nigam, A Review on the Potential Applications of Curved Geometries in Process Industry, Industrial \& Engineering Chemistry Research 47 (2008) 3291-3337. doi:10.1021/ie701760h.

[43] Verein Deutscher Ingenieure und Gesellschaft Verfahrenstechnik und Chemieingenieurwesen, VDI-Wärmeatlas, Springer Vieweg, Berlin, 2013.

[44] F. Garcia, R. Garcia, J. Padrino, C. Mata, J. Trallero, D. Joseph, Power law and composite power law friction factor correlations for laminar and turbulent gas-liquid flow in horizontal pipelines, International Journal of Multiphase Flow 29 (2003) 1605-1624. doi:10.1016/S03019322(03)00139-3.

[45] Y. Taitel, A. Dukler, A model for predicting flow regime transitions in horizontal and near horizontal gas-liquid flow, AIChE Journal 22 (1976) 47-55. doi:10.1002/aic.690220105. 